\title{
A CONSTITUIÇÃO DA AGRICULTURA FAMILIAR COMO CATEGORIA POLÍTICA: UMA LEITURA A PARTIR DAS LUTAS DO SINDICALISMO RURAL DO SUL DO BRASIL
}

\author{
Régis da Cunha Belem* \\ Renata Menasche**
}

\begin{abstract}
Resumo
A partir do sul, este artigo conduz o olhar à segunda metade da década de 1980, mais especificamente ao momento inicial de constituição, no país, da agricultura familiar como categoria política. Culminava, então, um processo de lutas por preços de produtos, política agrícola, reforma agrária e política previdenciária, conflagradas sob tom de denúncia dos efeitos perversos da "modernização conservadora" e do regime que a promovera. É nesse contexto que a diferenciação entre pequenos, médios e grandes produtores no acesso a políticas públicas - erguida como bandeira em 1987, na jornada de lutas do sindicalismo rural de pequenos agricultores gaúchos em que se deu a conquista da não cobrança de juros correspondentes a financiamentos agrícolas referentes ao período do Plano Cruzado - viria a compor a pauta de reivindicações dos Sindicatos de Trabalhadores Rurais no debate sobre a Lei Agrícola, que teve por palco o Congresso Nacional nos anos 1989-91. No período pós-Constituinte, o reconhecimento da demanda por políticas públicas diferenciadas levaria à institucionalização de políticas públicas dirigidas a este público específico. A agricultura familiar passava, assim, a compor o vocabulário de agentes de governo, enquanto que a criação do Pronaf pode ser interpretada como expressão do reconhecimento, pelo estado, da pertinência da diferenciação. Este estudo inscreve-se, portanto, no esforço de revisitar o debate sobre a constituição da categoria agricultura familiar no Brasil, buscando especialmente identificar a contribuição do sindicalismo rural do sul do Brasil para a constituição dessa categoria política e analítica.
\end{abstract}

Palavras-chave: Agricultura familiar. Políticas públicas. Movimentos sociais no campo.

\footnotetext{
* Mestre em Ciências Sociais em Desenvolvimento, Agricultura e Sociedade pela Universidade Federal Rural do Rio de Janeiro (UFRRJ). Doutorando em Desenvolvimento Rural na Universidade Federal do Rio Grande do Sul (UFRGS). Docente do curso de Bacharelado em Desenvolvimento Rural e Segurança Alimentar. Vinculado ao Instituto Latino-Americano de Economia, Sociedade e Política (ILAESP/UNILA). Email: regis.belem@unila.edu.br

** Doutora em Antropologia Social pela Universidade Federal do Rio Grande do Sul (PPGAS/UFRGS). Professora do Programa de Pós-Graduação em Antropologia da Universidade Federal de Pelotas (PPGAS/UFPel) e do Programa de Pós-Graduação em Desenvolvimento Rural da Universidade Federal do Rio Grande do Sul (PGDR/UFRGS). Email: renata.menasche@pq.cnpq.br
} 


\section{Introdução}

Agricultura familiar, termo de ampla circulação no Brasil desde o início dos anos 1990, é empregado como categoria política, categoria analítica ou a partir de perspectiva normativa; nas lutas do sindicalismo de trabalhadores rurais e de movimentos sociais, no ambiente acadêmico ou na ação do estado.

Análises da produção bibliográfica sobre produção familiar e estrutura agrária brasileira, realizadas nos anos 1980 e abarcando as duas décadas precedentes, não identificam a presença do termo agricultura familiar (NEVES, 2007). A instituição, no ano de 1995, do Programa Nacional de Fortalecimento da Agricultura Familiar (Pronaf) inaugura no âmbito da ação estatal a utilização desta "categoria genérica de designação" (NEVES, 2007), expressão do reconhecimento da necessidade de políticas agrícolas diferenciadas para um público específico.

Desde o sul, este trabalho conduz o olhar para a segunda metade da década de 1980, momento inicial de constituição da agricultura familiar como categoria política, quando culminava - sob tom de denúncia dos efeitos perversos da "modernização conservadora" e do regime que a promovera - um processo de lutas por preços de produtos, política agrícola, reforma agrária e política previdenciária. Nesse contexto, a diferenciação entre pequenos, médios e grandes produtores no acesso a políticas públicas - que fora erguida como bandeira em jornada de lutas de pequenos agricultores gaúchos, levada a cabo em 1987, quando da conquista da não cobrança de juros correspondentes a financiamentos agrícolas referentes ao período do Plano Cruzado ${ }^{1}$ - viria a compor a pauta de reivindicações dos Sindicatos de Trabalhadores Rurais (STRs) no debate sobre a Lei Agrícola, que teve como palco, no período de 1989 a 1991, o Congresso Nacional.

O presente artigo $^{2}$ insere-se, assim, no esforço de revisitar o debate sobre a constituição da categoria agricultura familiar no Brasil, indagando sobre o papel desempenhado pelos movimentos sociais rurais, pela academia e pelos agentes de estado na constituição dessa categoria, bem como a relação estabelecida entre essas distintas redes de atores (SILVA, 2015). Busca-se aqui identificar, especialmente, qual teria sido a contribuição do sindicalismo rural do sul do Brasil para a constituição dessa categoria política e analítica.

\section{As Lutas de 1987}

As Lutas de 87 representam o culminar de um processo iniciado em 1980, com o movimento que ficou conhecido como Luta contra o Confisco da Soja. À época, após duas safras de soja frustradas - devido à seca; baixos preços pagos pelo produto, associados à queda do preço internacional; redução do subsídio aos juros dos financiamentos agrícolas -, o governo
1 O Plano Cruzado constituiuse em um conjunto de medidas econômicas lançadas no final de fevereiro de 1986, quando governava o país o Presidente Sarney. Entre essas medidas, constavam: congelamento de preços de bens e serviços, criação das Obrigações do Tesouro Nacional (OTN) com fixação de seu valor pelo prazo de um ano, congelamento da taxa de câmbio, reforma monetária com criação do Cruzado em substituição ao Cruzeiro.

2 Vale mencionar que este trabalho é resultado de pesquisa conduzida no âmbito da elaboração da tese de doutorado do primeiro autor e que uma primeira versão foi submetida à discussão no Grupo de Trabalho Movimentos sociais, organizaçôes de representação e lutas por direitos no campo, durante o XVII Congresso Brasileiro de Sociologia, realizado em Porto Alegre, em 2015. 
decidira criar um imposto sobre as exportações do grão, o Confisco da Soja. Isso se deu justamente no início do que prometia ser uma safra positiva, que combinava boa produção e bons preços, momento em que havia, entre os agricultores, expectativa de recuperação dos prejuízos do período anterior (MENASCHE, 1996).

A Luta contra o Confisco da Soja, conflagrada em março de 1980, reuniu sindicatos de trabalhadores rurais organizados na Federação dos Trabalhadores na Agricultura no Rio Grande do Sul (Fetag), a agremiação sindical patronal Federação da Agricultura do Rio Grande do Sul (Farsul) e a Federação das Cooperativas de Trigo e Soja do Rio Grande do Sul (Fecotrigo), envolvendo, segundo reportado pela imprensa, mais de 700 mil pessoas, em 100 municípios. Mobilizando um repertório de lutas que abarcou passeatas, máquinas agrícolas nas ruas, trancamento de bancos, de rodovias etc., tomaram parte do movimento pequenos, médios e grandes produtores. Segundo Menasche (1996, p. 26), eram vários os setores envolvidos, mas, analisando as notícias da época [...], podemos perceber que as mobilizações realizadas tiveram, através de gestos, músicas, palavras de ordem, encenações e outras manifestações, uma 'marca' dos colonos.

Entre esses dois momentos, 1979/1980 e 1987, em que se realizaram, respectivamente, a Luta contra o Confisco da Soja e as Lutas de 87, inúmeras ações contestatórias foram desenvolvidas no Rio Grande do Sul, tendo como foco preços de produtos agrícolas e/ou crédito rural, mobilizando as regiões e cidades-polo em que se desenvolvia a atividade agrícola em questão (ver Quadro 1).

Quadro 1 - Mobilizações rurais ocorridas no Rio Grande do Sul no início dos anos 1980

1979: (1) Santa Cruz do Sul, fumo - congresso com mil fumicultores de trinta municípios; (2) Santa Bárbara, soja - pequenos sojicultores bloqueiam agência bancária e prefeitura;

1980: (1) Regiões sojicultoras - movimento contra o confisco da soja; (2) Frederico Westphalen, suínos - encontro estadual de suinocultores centrado nos abates indiscriminado de suínos (peste suína africana); (3) Estado do Rio Grande do Sul, suínos - suinocultores suspendem a venda do produto e realizam piquete nas estradas; (4) Caxias do Sul/Bento Gonçalves, uva/vinho - assembleia com cinco mil viticultores;

1981: (1) Bento Gonçalves, uva/vinho - concentração de quatro mil viticultores;

1982: (1) Estado do Rio Grande do Sul, leite - assembleia em Porto Alegre, com dez mil produtores de leite que decidem pelo boicote à venda do produto; (2) região viticultora, uva/vinho - assembleia com cinco mil agricultores;

1983: (1) Santa Cruz do Sul, fumo - congresso com dois mil fumicultores;

1984: (1) Estado do Rio Grande do Sul, agosto - manifestação, em Porto Alegre, com dois mil pequenos agricultores; (2) Estado do Rio Grande do Sul, Semana da Pátria - boicote à venda da produção dos pequenos agricultores; (3) Estado do Rio Grande do Sul, outubro - Grito do Campo, organizado pela Fecotrigo, reúne, em Porto Alegre, 40 mil pessoas entre pequenos, médios e grandes produtores, sindicalistas e cooperativas, para entregar pauta de reivindicações a candidatos à Presidência da República (Tancredo Neves).

Fonte: Menasche (1996, p. 31). 
Segundo Menasche (1996), as mobilizações do período expressavam percepção de crise entre os pequenos agricultores cujas práticas agrícolas haviam sido transformadas a partir de sua adesão ao projeto modernizador implementado pelo estado brasileiro. Tal processo de transformação da agricultura deu-se a partir da segunda metade da década de 1960, com a incorporação de novas tecnologias de produção agrícola - o dito pacote da Revolução Verde -, financiada com crédito barato. A subsequente crise de financiamento do estado desembocaria na opção pela redução de volume de recursos e de subsídios do crédito rural, com consequente queda de rentabilidade dessa agricultura. Em sua pesquisa, a autora citada analisa como esse processo se deu na região noroeste do Rio Grande do Sul, evidenciando as percepções da crise a partir de manifestações de distintos agentes sociais a respeito dos impactos (negativos) da agricultura modernizada voltada à produção de commodities (trigo, soja, suínos, leite), em uma leitura crítica à monocultura.

No início dos 80, tendo como marco a luta contra o confisco da soja, ocorria [...] um revigoramento da ação sindical dos agricultores familiares do Sul. Nesse processo de afirmação política, centrado no enfrentamento ao Estado, algumas oposições iam sendo construídas: produção para subsistência e/ou produção de alimentos versus monocultura, pequenos versus grandes. (MENASCHE, 1996, p. 24-25).

É interessante observar que, no discurso crítico aos impactos da Revolução Verde, ao tempo em que a monocultura de soja aparece como expressão da modernização e causa da crise, ao discutir a adesão de casos particulares à monocultura, os agricultores por ela indagados atribuem a outros essa prática:

foi sempre 'o outro' quem aderiu à monocultura. Foi o vizinho. Para os de longe da cidade, foram os de perto da cidade. Para os da terra dobrada, foram os da terra vermelha, terra de maquinário. Mas os agricultores de perto da cidade e os da terra vermelha dizem que em sua realidade isso não aconteceu: foram os agricultores de outros municípios, ou os do Paraná, ou foram aqueles que nem eram agricultores, eram gente do comércio (MENASCHE, 1996, p. 15).

No mesmo sentido, Menasche (1996) indica que, com a expansão da produção de soja, foram mantidas áreas voltadas à produção para subsistência, que, ainda que reduzida em relação a épocas anteriores, era afirmada como de grande importância, sendo contundente a crítica àqueles que plantam soja até na soleira da porta e compram mandioca descascada no mercado.

Como expressão do processo de redemocratização, que então caracterizava o cenário político nacional, no período 1979-84 realizaram-se 
diversas mobilizações. No entanto, talvez em decorrência de expectativas diante do processo de mudanças em curso em âmbito nacional (após o movimento pelas eleições diretas, eleição e morte de Tancredo Neves, posse de José Sarney e início da "Nova República"), elas não seguiriam no mesmo ritmo nos anos 1985/1986. Vale comentar que a ação expressiva realizada no ano de 1985 não teve como foco demandas por preços ou política agrícola, mas reconhecimento social: em 17 de outubro de 1985 foi realizado o $1^{\circ}$ Encontro do Movimento Estadual das Mulheres Trabalhadoras Rurais que seria conhecido como "Movimento das Margaridas" -, reunindo, em Porto Alegre, o impressionante número de dez mil mulheres.

O primeiro ano da Nova República, 1985, foi marcado pelo que foi considerada a maior seca até então ocorrida no Rio Grande do Sul. No plano nacional, iniciavam-se os debates sobre a Assembleia Nacional Constituinte.

Em 1986, foi editado o Plano Cruzado, que visava à inflação zero e congelava preços. No meio do ano, antecedendo a época do plantio, foi lançado o "pacote verde", com medidas para o setor agrícola, buscando alavancar a produção e sustentar o Plano Cruzado, a fim de oferecer previsibilidade ao setor por meio de medidas de médio prazo - o pacote deveria vigorar por três anos. Entre as medidas anunciadas, estavam os juros fixos para empréstimos de custeio das lavouras.

Na sequência das eleições de novembro de 1986, tendo sido eleitos os deputados constituintes, foi lançado o Plano Cruzado II. Uma das medidas do plano "descongelava" as OTNs, indexador dos contratos de crédito rural. Desse modo, os juros do crédito rural, que no início da safra (julho) haviam sido anunciados como fixos, tiveram uma elevação de 70\% apenas entre os meses de novembro de 1986 e março de 1987, enquanto os preços dos produtos agrícolas e a taxa de câmbio eram mantidos congelados.

Apesar do anúncio das medidas ter ocorrido em novembro, apenas no final de fevereiro e começo de março, quando os agricultores tiveram contato com os valores atualizados de suas dívidas, a serem pagas com a colheita que teria início na segunda metade de março, tem início a agitação junto aos STRs. O mês de março seria tomado por reuniões de sindicatos, de associações regionais de sindicatos, da Federação Estadual (Fetag), de segmentos patronais e de cooperativas. Após algumas tentativas, frustradas, de realização de reuniões com Ministérios em Brasília, o movimento foi deflagrado no final do mês de março de 1987, com uma adesão massiva sem precedentes - de agricultores.

O processo de mobilização e luta pela queda da correção monetária nos financiamentos agrícolas teve o protagonismo da Central Única dos Trabalhadores (CUT) e da Fetag, a partir de uma dinâmica que envolveu, no Rio Grande do Sul, a busca de adesão e diferenciação entre setores 
que representavam os pequenos e os grandes agricultores, entre a CUT e a Fetag, entre diferentes correntes sindicais no interior da CUT.

Entre os dias 30 de março e 3 de abril de 1987, em torno de 250 mil pequenos agricultores gaúchos participaram dos protestos. A amplitude e radicalidade do movimento foram significativas a ponto de mobilizar os centros de poder estadual e federal. No dia $1^{\circ}$ de abril, quarta-feira, o Ministro da Fazenda Dilson Funaro acenara com uma reunião com os agricultores, enquanto o Exército era acionado pela Presidência da República para - empregando seu efetivo, metralhadoras, fuzis e tanques - desobstruir rodovias. No dia seguinte, seria anunciado o atendimento parcial da principal reivindicação ${ }^{3}$, quando o trancamento de estradas era finalizado, com a intensificação da intervenção do Exército e da Brigada Militar.

Após o término da mobilização dos pequenos agricultores que alcançara ampla repercussão nos meios de comunicação -, suas organizações não conseguiram dar continuidade à negociação do principal item reivindicado. $\mathrm{O}$ processo passaria a ser conduzido por organizações representativas de médios e grandes produtores rurais, a Frente Ampla da Agropecuária (constituída em fevereiro de 1987) e a União Democrática Ruralista (UDR), distanciando-se das demandas que haviam sido reivindicadas nas ruas e estradas antes ocupadas por pequenos agricultores, passando a ter como palco os gabinetes, em Brasília ${ }^{4}$.

Procurando compreender as motivações que, em 1987, mobilizaram os agricultores na luta pela queda da correção monetária, Menasche (1996) recorre a perspectivas analíticas propostas por Edward P. Thompson e James $S \operatorname{cott}{ }^{5}$, construindo o entendimento de que, para além da dimensão econômica, estavam em questão a legitimidade e justiça da medida. Após as expectativas criadas com o início da Nova República e com o Plano Cruzado, que haviam sinalizado um período de estabilidade para a produção agrícola, com juros fixos nos financiamentos agrícolas, os agricultores foram surpreendidos pela alteração da regra do jogo, com repentina e significativa elevação de juros não sobre empréstimos futuros, mas sobre empréstimos já contratados, correspondentes à safra que estava por ser colhida. Em suas palavras, “[...] não havia justiça naquela correção monetária que não havia sido previamente acordada, ela era ilegítima, era considerada ilegal. Os agricultores acreditavam ter o direito de não pagá-la" (MENASCHE, 1996, p. 46).

\section{Precisões e abordagens}

Tendo presente a criação do Pronaf, em 1995, quando Agricultura Familiar passou a constituir-se enquanto categoria normativa que compõe
3 Suspensão da cobrança da correção monetária sobre os empréstimos de emergência realizados em decorrência da seca de 1985.

4 Note-se que, enquanto o atendimento da reivindicação dos pequenos agricultores custou aos cofres públicos o valor de 2,5 bilhões de cruzados, a anistia das dívidas dos grandes produtores drenou 26 bilhões de cruzados, um valor dez vezes superior (MENASCHE, 1996, p. 40).

5 As obras citadas pela autora nessa análise são as que seguem: THOMPSON, Edward P. La economía "moral" de la multitud en la Inglaterra del siglo XVIII. In: Tradición, revuelta y consciencia de clase: estudios sobre la crisis de la sociedad preindustrial. Barcelona, Critica, 1989; SCOTT, James. The moral economy of the peasant: rebellion and subsistence in Southeast Asia. New HavenLondon, Yale University Press, 1976. 
6 Para um balanço das políticas públicas para a agricultura familiar desenvolvidas nas décadas recentes, ver, entre outros, Grisa e Schneider (2015). o aparato de estado para intervenção sobre um setor social específico, este trabalho debruça-se sobre o período anterior, a década de 1980, quando o movimento sindical de trabalhadores rurais do sul do Brasil (no caso, Rio Grande do Sul) desenvolve um processo de lutas que contribui para forjar a identidade de "pequeno agricultor", em oposição a médios e grandes "produtores". A luta por uma "nova política agrícola", em que é defendida uma "política agrícola diferenciada", que distinguisse pequenos, médios e grandes a partir de proposições normativas surgidas nas Lutas de 87 e retomadas no debate sobre a Lei Agrícola (1989-1991), parece constituir-se no antecedente imediato do Pronaf, expressão do reconhecimento estatal da pertinência dessa diferenciação e iniciativa pioneira na institucionalização de política pública dirigida a este público específico ${ }^{6}$.

Não é extensa a literatura que aborda o sentido das lutas por política agrícola que se desenvolveram ao longo dos anos 1980, sendo que nesse quadro diferencia-se a pesquisa que resultou na dissertação de mestrado de Menasche (1996), Percepções e projetos: agricultura familiar em mudança, realizada a partir da região noroeste do Rio Grande do Sul e concluída à época do início da execução do Pronaf. Esse trabalho abarcou desde aspectos associados às condições econômicas da produção agrícola do período, elementos de política econômica e de política agrícola, até aspectos relativos às condições sociais e políticas, em que têm destaque as narrativas da crise e suas relações com as mudanças ocorridas nos modos de viver e trabalhar daqueles agricultores, assim como as mobilizações realizadas no período - com destaque para as Lutas de 87-, parte mais visível do processo de formação do ator coletivo.

Já Brumer (1990), que analisara as lutas sociais no campo ocorridas na década de 1978-88 no extremo sul do Brasil, simplesmente não menciona a ocorrência das Lutas de 87, restringindo, em sua análise, demandas vinculadas à produção a lutas por preços de produtos agrícolas.

Outros trabalhos se debruçaram sobre a constituição do sindicalismo rural cutista (Rio Grande do Sul e Brasil) em sua relação com o sistema contaguiano (federação e confederação), mas sempre enfatizando a reconfiguração da estrutura sindical do campo, a exemplo de Schmitt (1996), Favareto (2006) e Picolotto (2014a, 2014b). Entre esses, Schmitt (1996) é a única autora a registrar, ainda que sinteticamente, a ocorrência das Lutas de 1987.

Desse modo, notamos que as mobilizações conduzidas durante os anos 1980 pelo sindicalismo rural gaúcho (cutista e fetaguiano), que demandavam preços de produtos agrícolas, política agrícola, saúde e previdência, parecem não ter exercido grande influência sobre a orientação das reflexões dos pesquisadores desse rural. Mas, também referente aos anos 1980, há ampla produção acadêmica abordando a luta pela terra e movimentos sociais a 
ela associados. Tal distinção não pode ser interpretada como reflexo de uma menor ocorrência, no campo gaúcho do período, de mobilizações que reivindicavam condições de produção (preços e política agrícola) em relação às que reivindicavam acesso a terra, mas sim das condições em que se colocava, à época, o debate político, mais especificamente à oposição estabelecida entre luta revolucionária (associada a movimentos por reforma agrária) e luta reformista (associada a movimentos por política agrícola).

No bojo do processo de democratização, no final dos anos 1970 e início dos anos 1980, com ascensão das mobilizações populares, a oposição entre luta revolucionária e luta reformista, tal como antes mencionada, apresentava-se como forma de atualização aos contextos rurais da época de debate forjado em processos revolucionários "clássicos". Analisando a trajetória de "movimentos sociais" enquanto tema da pesquisa e partindo da dicotomia, presente nos anos 1980, entre novos e velhos movimentos sociais, Medeiros (2012, p. 9) aponta que, sob o modelo de "movimento revolucionário", o agente de mudança social e política por excelência seria o movimento operário (pertencente ao "velho" movimento social). A autora indica que essa ênfase perdura até os anos 1960, tendo aí destaque o pensamento marxista. Alexander (1998) identifica essa perspectiva ao "modelo clássico" de interpretação dos movimentos sociais. Para o caso brasileiro recente, Medeiros (2012, p. 12) sublinha a concomitância do surgimento do "novo movimento social" com o "novo sindicalismo", do qual o sindicalismo rural cutista foi expressão (SCHMITT,1996; FAVARETO, 2006; PICOLOTTO, 2014a, 2014b). Ao final da década de 1980, este debate permanecia presente, tanto é que, no interior da CUT, seguia sendo alvo de questionamento a própria presença dos "pequenos agricultores" no interior da Central. Esse debate, que remetia à reflexão sobre classes e alianças de classe, foi registrado pela Revista Teoria \& Debate ${ }^{7}$. No mesmo sentido, Abers e Von Büllow (2011, p. 79) identificam, nas décadas de 1960 e 1980, a ocorrência do debate "[...] sobre quais movimentos eram legítimos, realmente transformadores, ou relevantes socialmente".

Pretendemos, então, evidenciar o protagonismo, ao longo de uma década de lutas, do sindicalismo rural do sul do Brasil, em que a CUT cumpriu papel de destaque (em relação com o sistema confederativo Contag), em convergência com iniciativas de agentes do estado e com iniciativas no âmbito da academia. Diferentemente, por exemplo, do que propôs Neves (2005, p. 23), que afirma que o “[...] termo agricultura familiar corresponde [...] à convergência de esforços de certos intelectuais, políticos e sindicalistas articulados pelos dirigentes da Confederação Nacional dos Trabalhadores na Agricultura" ${ }^{8}$ - privilegiando a iniciativa de intelectuais -, a ênfase aqui proposta recai sobre o movimento social, que aporta o contexto efervescente no qual a ação da academia encontra terreno fértil
7 Venceslau (1989) e Novaes (1989).

8 A respeito, cabe ter presente a contribuição de Picolotto (2014b), que trata do processo de construção da categoria agricultura familiar no Brasil contemporâneo identificando três conjuntos de atores que promoveram tal construção: (a) o debate acadêmico promovido à época; (b) as políticas do Estado e as normativas legais; (c) as organizações de agricultores familiares. 
para o debate teórico, e em que agentes de estado sensíveis à demanda social e ao engajamento de pesquisadores fornecem o suporte institucional para a configuração da política pública.

Propõe-se, aqui, analisar essa convergência por meio do estudo sobre as fronteiras entre movimentos sociais, sociedade civil e estado, abordagem que, acreditamos, poderá oferecer novos elementos para a compreensão do processo de constituição da agricultura familiar como categoria com múltiplas apreensões pelos diferentes atores envolvidos.

Para tanto, valemo-nos de proposições sugeridas por Marcelo Kunrath Silva (2015). Seguindo o caminho trilhado por esse autor, percebemos que inicialmente adota uma definição de movimentos sociais não como atores, mas como redes de atores. Dessa maneira, Silva busca preservar a diversidade dos atores envolvidos na rede movimentalista e a complexidade das relações que são estabelecidas. Tomamos a definição de movimentos sociais elaborada por Diani (2000, p. 389 apud SILVA, 2015, p. 141), que explica:

\footnotetext{
"[R]edes informais de atores (organizações, grupos e indivíduos) engajadas em conflitos pelo controle de recursos materiais ou simbólicos, baseadas em identidades compartilhadas". Assim, enquanto rede, o movimento social é (re)produzido pelas ações e relações de um conjunto diversificado de atores (centralmente, organizações sociais e ativistas), que têm como ponto de identificação o reconhecimento do pertencimento a uma determinada posição dentro de um campo de interações (em parte, conflitivas) com outros atores. Essa definição, como se pode observar, não estabelece nenhuma demarcação a priori nem dos espaços sociais de pertencimento e atuação nem dos repertórios de ação dos atores que conformam as redes apreendidas através do conceito de movimentos sociais.
}

A partir dessa contribuição, conduziremos novamente o olhar ao processo de mobilizações do sindicalismo rural gaúcho, ocorridas a partir dos 1980, agora o tomando como movimento social e trazendo à análise a abordagem que percebe movimento social como rede de atores.

\section{Antecedentes e bastidores das Lutas de 87}

Tendo sido constituído no período pós-1964 sob a tutela do estado e iniciativa de organizações sob a influência da Igreja Católica, como a Frente Agrária Gaúcha (FAG), o sindicalismo de trabalhadores rurais no Rio Grande do Sul passou por um processo de revigoramento, forjado pelas lutas do início dos 1980, tal como a luta contra o confisco da soja. A utilização do dia 31 de março - àquela época ainda importante data comemorativa da Revolução, ou melhor, do Golpe Militar de 1964 - como 
data de protestos e mobilizações de agricultores não deve ser interpretada como coincidência.

No período entre 1979/1980 e 1987, o conjunto das lutas desenvolvidas no Rio Grande do Sul com a participação dos sindicatos de trabalhadores rurais - centradas em preços de produtos agrícolas, crédito rural, previdência social ou reforma agrária - enfatizou a condição de "pequeno agricultor" e a denúncia de seus problemas, compondo discursos, palavras de ordem, cartazes, publicações. Ressaltamos esse elemento para destacar que o processo de lutas do período contribuiu para forjar a identidade "pequena agricultura" - que, nos anos 1990, seria atualizada como "agricultura familiar".

O ineditismo das Lutas de 87 deu-se na condução do processo de mobilização, que se distanciava do conjunto de "produtores", que englobava médios e grandes como participantes do mesmo setor, a agricultura (ou agropecuária).

Os diferentes atores então participantes da rede movimentalista utilizaram distintos expedientes no jogo pela busca de adesão - mas também de diferenciação - em relação aos demais setores participantes (representação dos pequenos ou grandes agricultores, da CUT ou da Fetag, das diferentes correntes sindicais no interior da CUT): definição sobre a instância legítima para decisão sobre a mobilização (que incluía ou excluía um estrato social ou corrente política), definição sobre a data mais apropriada para a realização da manifestação (buscando coincidir - ou no mais das vezes antecipar-se - com a iniciativa de outro ator), a pauta de reivindicações, diferentes aspectos que compunham o repertório acionado serviam para o jogo de adesão/diferenciação. $O$ conteúdo da pauta de reivindicações foi o principal objeto de distinção dos "pequenos agricultores”. Nela, constava a proposição de diferenciação dos agricultores pelo volume de produção e pela área total da propriedade? .

A luta contra a correção monetária contou com a participação de diferentes atores. A direção do movimento foi dada pela CUT, por intermédio de sua Secretaria Rural, e pela Fetag, combinando iniciativas articuladas, concorrentes e paralelas. A mobilização contou também com o envolvimento de organizações representativas de médios e grandes produtores, mas em tempos e espaços distintos.

O processo de busca de adesão, mas também de diferenciação entre atores foi refletido (1) nas estratégias de mobilização que visavam à adesão dos pequenos agricultores atingidos pela medida, incorporação de outras correntes sindicais, apoio da sociedade regional, sensibilização do governo federal; (2) nas táticas de negociação com o governo federal (Ministério da Fazenda).
9 Esta questão, referente aos critérios que melhor expressam a diferenciação dos pequenos agricultores frente aos demais, percorrerá o processo Constituinte, sendo retomada quando do debate sobre a Lei Agrícola. Apenas na metade da década de 1990 o estado viria a regulamentar a matéria, com a edição do Pronaf. 
10 A respeito da presença do sindicalismo rural na CUT, temos que em seu $1^{\circ}$ Congresso Nacional, em 1984, o "setor rural foi responsável pela maior representação setorial, superando inclusive os trabalhadores da indústria" (FAVARETO, 2006, p. 34). Ao longo da década de 1980, Favareto indica uma participação entre 30 e $40 \%$ de sindicalistas rurais nos congressos da Central e na composição de suas direções.

11 "Em 16 de março, em uma reunião da Secretaria Rural da CUT/RS, com a participação das Secretarias Rurais de três regionais da CUT (Missões, Alto Uruguai e Planalto), é elaborada uma pauta de reivindicações e um plano de lutas que seriam apresentados como proposta da CUT para o conjunto do movimento sindical gaúcho na Assembléia [sic] da FETAG, que se realizaria no dia seguinte" (MENASCHE, 1996, p. 36).
O protagonismo da CUT foi evidente no processo e exemplifica o que exposto anteriormente. A CUT havia, no ano anterior (junho de 1986), realizado seu segundo congresso estadual, em que questões referentes ao sindicalismo rural, na perspectiva da construção do sindicalismo cutista no campo, tiveram repercussão entre os sindicatos presentes, urbanos e rurais ${ }^{10}$. Um dos temas que então polarizou o debate era referente à relação a ser estabelecida com a Fetag: a construção da CUT no campo gaúcho deveria contemplar uma atuação "por dentro" da Federação, ou não. Com divisões no interior dos sindicatos rurais presentes, o conjunto dos delegados do congresso decidiu por uma estratégia de construção que considerava a participação na Fetag.

Ainda que sintético, o resgate dos antecedentes deste processo, parece-nos importante para melhor compreender a deflagração, condução e negociação do movimento reivindicatório, bem como sua posterior avaliação pelos atores envolvidos.

O início do processo de mobilização, na sua expressão por meio de manifestações públicas, ocorreu na primeira metade do mês de março, deixando perceber as estratégias diversas definidas pelos diferentes campos políticos no interior dos "rurais" da CUT/RS: com protagonismo da CUT, a região do Alto Uruguai marcou a primeira mobilização para o dia 5 de março e a região das Missões marcou para os dias 9 e 10 de março. À época, não conseguiram chegar a um acordo com relação à data da mobilização. De todo o modo, essas mobilizações prestaram-se a promover o debate sobre a pauta de reivindicações e "preparar o clima" para a assembleia da Fetag, que se realizaria no dia 17 de março. Na assembleia da Federação, seguindo política definida no mais recente congresso da CUT, os STRs cutistas apresentaram e submeteram documento conclamando à luta e propondo uma pauta de reivindicações - que seria aprovada quase que na íntegra -, bem como a decisão de ir para as ruas ${ }^{11}$.

Outro fato positivo foi que os Sindicatos ligados à CUT foram à Assembléia [sic] da FETAG no dia 17/03 com uma proposta clara e definida. A distribuição desta proposta, com o timbre da CUTRS aos participantes, provocou algumas reações contrárias, mas no final todas as propostas apresentadas foram aprovadas. Sabemos que são poucos os Sindicatos identificados com a CUT no meio rural, mas ainda assim deu prá disputar com a FETAG a direção da luta. (CUT/RS, 1987, p. 3).

Como afirmado anteriormente, a dinâmica de mobilização envolveu a busca de adesão e diferenciação entre as diversas correntes sindicais no interior da CUT, entre a CUT e a Fetag, e entre setores que representavam os pequenos e os grandes agricultores. $\mathrm{O}$ fato de setores da CUT realizarem manifestações nos dias 5 e 9/10 de março também marcava antecipação 
em relação à mobilização de setores patronais, pois a Frente Ampla da Agropecuária havia marcado mobilizações para o dia 10 de março (MENASCHE, 1996).

Enquanto que nas mobilizações ocorridas no início do mês de março uma comissão exclusiva da CUT tentara, sem sucesso, abrir canal de negociação em Brasília, nas mobilizações ocorridas no final daquele mês a negociação seria realizada por uma comissão da Fetag, em cuja composição havia representantes de STRs cutistas, que teriam papel destacado na condução e desfecho da negociação (MENASCHE, 1996).

\section{Pistas para uma interpretação}

Como visto, desde o início dos anos 1980 um conjunto de atores colocara-se em relação no processo de contestação às medidas governamentais consideradas ilegítimas (confisco da soja e cobrança da correção monetária nos empréstimos agrícolas), ou na reivindicação por melhores preços, entre outras demandas. Grosso modo, a rede de atores constituída envolveu, em um primeiro momento, pequenos, médios e grandes agricultores, indistintamente, construindo ou acionando a identidade agricultores (ou, produtores), em oposição ao Governo; e, em um segundo momento, correntes internas à CUT e à Fetag, construindo ou acionando a identidade pequenos agricultores, em oposição ao Governo e aos grandes produtores.

Nessa perspectiva, as divergências e disputas sobre as datas de mobilização, ou sobre a redação de itens de pauta de reivindicações, ou sobre posições conflitantes em congressos e até mesmo sobre a composição de direções, para além de expor as disputas intestinas do movimento sindical rural, mostram os meandros do campo de interações - mesmo conflitivas que conformam a construção do movimento social enquanto rede de atores, atores esses que são diversos.

A partir do argumento de Silva (2015, p. 141), que propõe que “[...] ao definir que um dos atores centrais das redes movimentalistas são grupos e organizações sociais, esse conceito estabelece o pressuposto de que movimentos sociais possuem um necessário enraizamento no tecido associativo societário", cabe atentar para o papel desempenhado pelos Sindicatos de Trabalhadores Rurais no movimento reivindicatório. Como anteriormente abordado, os STRs foram constituídos no período pós1964 sob a influência da Igreja Católica e tutela do estado, a fim de formar uma barreira ao "perigo do comunismo" expresso na experiência das Ligas Camponesas, desenvolvida, à época, no Nordeste do Brasil. Apesar das motivações que lhe deram origem, podemos afirmar que este sindicalismo rural se enraizou no "tecido associativo societário", conforme a perspectiva proposta por Silva. 
12 Lembremos que as cooperativas tradicionais de produção estiveram à frente da luta contra o confisco da soja (1980) e no Grito do Campo (1984).

13 Analisando a história recente do "novo sindicalismo rural" no Brasil, Favareto (2006, p. 38) identificava haver, em meados da década de 1980, uma estratégia de construir o sindicalismo cutista "por fora" da estrutura oficial - leia-se, Contag. Picolotto (2014a) evidencia a presença dessa perspectiva no sul do Brasil por meio da atuação da Articulação Sindical Sul, corrente que não era majoritária na CUT/ RS (GEA, 1986, 1987).

14 Consta do Art. 50 do Ato das Disposições Constitucionais Transitórias da Constituição Federal: "Lei agrícola a ser promulgada no prazo de um ano disporá, nos termos da Constituição, sobre os objetivos e instrumentos de política agrícola, prioridades, planejamento de safras, comercialização, abastecimento interno, mercado externo e instituição de crédito fundiário".
Por outro lado, também aqui é possível “[...] pensar movimentos sociais como redes complexas que podem transcender fronteiras entre distintos espaços sociais, tais como o Estado e o mercado, integrando atores desses espaços como parte constitutiva dos movimentos" (SILVA, 2015, p. 141). Nas mobilizações de 1987 (e mesmo na luta contra o confisco da soja e outras), observamos a adesão ao movimento por parte dos poderes públicos locais (câmaras de vereadores, prefeituras municipais), com fechamento de repartições públicas, e mesmo a adesão de comércio local (associações comerciais e industriais), com o fechamento de estabelecimentos. Ainda, tendo presente, nas mobilizações em questão, as relações entre movimento social e mercado, mesmo as grandes cooperativas de produção, habitualmente politicamente conservadoras, acabaram por configurar-se como "agentes associativos, políticos e econômicos"12 (SILVA, 2015, p. 141).

Segundo Menasche (1996), nos anos seguintes (1988/1989) ocorreriam tentativas de reeditar mobilizações como aquela de 1987, mas com dinâmicas organizativas diferentes: a CUT estadual passaria a seguir orientações da Secretaria Rural da CUT nacional, deixando de buscar promover lutas conjuntas com a Fetag e privilegiando ações combinadas com o Movimento dos Trabalhadores Rurais Sem Terra (MST) e a Comissão Pastoral da Terra (CPT) (MENASCHE, 1996) ${ }^{13}$.

Após a promulgação da nova Constituição Brasileira, em outubro de 1988, a reivindicação de uma "nova política agrícola" migraria das ações direcionadas ao texto constitucional para o debate sobre a Lei Agrícola ${ }^{14}$. Entre outros temas, estabelecia-se outro espaço político para a retomada da necessidade de uma política diferenciada para os pequenos agricultores, atualizando o debate sobre critérios para a diferenciação entre pequenos, médios e grandes agricultores.

Desse modo, o Executivo deixou de ser, no período, o principal destinatário das preocupações dos sindicalistas rurais, voltados ao Legislativo, responsável pela elaboração e aprovação da Lei Agrícola.

Sem grandes mobilizações de rua, o espaço privilegiado de pressões e negociações passava a ser os corredores do Congresso Nacional, onde a dinâmica parlamentar adquire importância.

Aqui pode ser útil à análise a perspectiva proposta por Silva (2015) sobre intersecção entre política contestatória e política institucionalizada, que discorre sobre o limite dos tradicionais modelos analíticos utilizados por parte significativa da literatura que aborda as relações entre organizações/ movimentos sociais e Estado.

[O] pressuposto da externalidade, segundo o qual existe (ou deveria existir) uma separação clara entre movimentos sociais e Estado ou, em outras palavras, entre política contestatória e política 
institucional; e o pressuposto da confrontação, segundo o qual a atuação confrontacional é (ou deveria ser) a forma de ação por excelência dos movimentos sociais. (SILVA, 2015, p. 135).

Segundo o autor, encontramos esses pressupostos presentes na literatura sobre movimentos sociais, mais como obstáculos à apreensão das complexas relações entre movimentos sociais e estado. Constitui-se em exemplo o caso da literatura norte-americana, pois se conformou a partir do estudo de movimentos sociais paradigmáticos que possuíam a característica de seus integrantes encontrarem-se excluídos do processo político eleitoral, caso do movimento dos direitos civis dos negros durante as décadas de 1950 e 1960 (SILVA, 2015).

Para o caso brasileiro, as abordagens teóricas que analisaram os movimentos sociais das décadas de 1970 e 1980 tenderam a expressar uma visão dualista entre movimentos sociais e sistema político-institucional e não uma abordagem processual e relacional.

Tais perspectivas teóricas, enfatizando a externalidade dos movimentos sociais em relação aos atores e instituições políticoadministrativas e os repertórios de confronto como forma central (se não única) de atuação, mostraram-se relativamente pertinentes para abordar a formação e a atuação de movimentos sociais em contextos autoritários e excludentes. (SILVA, 2015, p. 139).

O envolvimento do sindicalismo rural no debate sobre a Lei Agrícola (e a Lei Agrária), no contexto de "redesenho" da estrutura sindical rural e a busca de "alternativas" para o campo, colocam em evidência a oportunidade e o desafio de analisar este processo considerando a complexidade das relações entre política contestatória e política institucionalizada.

Tal como sugere Silva (2015, p. 137), buscar a distinção entre atores, espaços sociais e repertórios de ação no conceito de movimento social, contribuiria para superar a imprecisão teórica gerada e "[...] forneceria instrumentos analíticos mais qualificados para abordar as complexas, heterogêneas e mutáveis relações entre movimentos sociais e Estado”.

\section{Considerações Finais}

Acionando a designação "pequeno agricultor", o sindicalismo rural gaúcho movimentou a década de 1980, com manifestações e lutas por preços “justos" para produtos agrícolas, crédito rural, política agrícola, saúde e previdência social. Nesse processo, tendo como ponto de partida grandes mobilizações realizadas conjuntamente com organizações de médios e grandes agricultores e marcadas pela oposição entre agricultura e setores urbanos (indústria, bancos), na metade final da década dá-se a distinção em 
relação aos grandes produtores, consubstanciada na reivindicação por uma política agrícola diferenciada para os pequenos agricultores. A partir dos estados do sul do Brasil - Rio Grande do Sul, em particular -, essa bandeira unificaria a luta de amplos setores sindicais rurais, que não se apresentavam de maneira coesa. A definição, organização e mobilização das lutas eram permeadas por posições diversas e projetos políticos em disputa. A rede de atores estabelecida no período envolveu não apenas as organizações sindicais, mas também o tecido associativo presente nos pequenos municípios, de forte base agrícola. Para tanto, distintos repertórios de luta e mobilização foram acionados, envolvendo desde a ocupação de espaços públicos (estradas, agências bancárias) até a ação no ambiente parlamentar (Assembleia Constituinte ou processo legislativo ordinário). Desse modo, as intersecções entre política contestatória e política institucionalizada dão a perceber sua complexidade, isso a partir da atuação, em ambos os polos, dos movimentos. Articulam-se, assim, o trancamento de estradas e a presença em um gabinete ministerial, em Brasília; a ocupação de uma agência bancária e a intermediação com o executivo federal por meio de um deputado federal (que conta com dirigentes sindicais na base de apoio que o elegeu). Do mesmo modo se articulam a dimensão contestatória presente na reivindicação da queda da correção monetária dos empréstimos bancários realizados por pequenos agricultores e a dimensão propositiva e institucionalizada presente na demanda por uma política agrícola diferenciada.

É, então, no contexto de intensa mobilização social por questões referentes à política agrícola que o debate acadêmico forja, em um processo de poucos anos, o termo agricultura familiar. A adesão ao termo por parte das duas grandes entidades sindicais nacionais - Contag e CUT será rápida, até porque próximas às relações entre movimentos sociais e academia. Ainda que mantido o termo pequeno agricultor como recurso de linguagem, será o termo agricultura familiar o considerado como mais representativo do projeto de sociedade defendido por lideranças e dirigentes dessas organizações rurais. A convergência na utilização do termo entre movimentos sociais rurais, pesquisadores e agentes do estado efetivou-se na metade da década de 1990, com a instituição do Pronaf, expressando o ponto de chegada também das mobilizações empreendidas pelo sindicalismo rural do sul do Brasil e seu projeto de política agrícola diferenciada, com ênfase no crédito rural.

O estudo das complexas relações estabelecidas nas fronteiras entre movimentos sociais, sociedade civil e estado, buscando a distinção entre atores, espaços sociais e repertórios, mostra-se assim promissor quando o pensamos aplicado a contextos rurais, no caso, o sindicalismo rural do sul do Brasil. 


\section{Referências}

ABERS, Rebeca; VON BULOW, Marisa. Movimentos sociais na teoria e na prática: como estudar o ativismo através da fronteira entre Estado e sociedade? Sociologias, Porto Alegre, v. 13, n. 28, p. 52-84, 2011.

ALEXANDER, Jeffrey. Ação coletiva, cultura e sociedade civil: secularização, atualização, inversão, revisão e deslocamento do modelo clássico dos movimentos sociais. Revista Brasileira de Ciências Sociais, v. 13, n. 37, p. 5-31, 1998.

BRUMER, Anita. Considerações sobre uma década de lutas sociais no campo no extremo sul do Brasil (1978-88). Ensaios FEE, v. 11, n. 1, p. 124-142, 1990.

CENTRAL ÚNICA DOS TRABALHADORES (RS) - CUT/RS. Secretaria Rural. Texto de avaliação da luta dos agricultores. Porto Alegre: CUT, 1987.

FAVARETO, Arilson. Agricultores, trabalhadores: os trinta anos do novo sindicalismo rural no Brasil. Revista Brasileira de Ciências Sociais, São Paulo, v. 21, n. 62 , p. $27-44,2006$.

GRISA, Catia; SCHNEIDER, Sérgio (Org.). Políticas públicas de desenvolvimento rural no Brasil. Porto Alegre: Editora da UFRGS, 2015.

GRUPO DE ESTUDOS E ASSESSORIA AGRÁRIA ( GEA). III Congresso da CUT-RS: um balanço do trabalho. Terragente, Porto Alegre, n. 40, p. 5-7, 1986.

13, 1987.

Rurais entram com tudo na CUT. Terragente, Porto Alegre, n. 41, p. 12-

MEDEIROS, Leonilde Servolo. Os movimentos sociais como campo de pesquisa nas ciências humanas. Revista Mundos do Trabalho, v. 4, n. 7, p. 7-31, 2012.

MENASCHE, Renata. Percepções e projetos: agricultura familiar em mudança - o caso da região de Santa Rosa, Noroeste do Rio Grande do Sul. 1996. 143 f. Dissertação (Mestrado de Ciências Sociais em Desenvolvimento, Agricultura e Sociedade), Universidade Federal Rural do Rio de Janeiro, Rio de Janeiro, 1996.

NEVES, Delma Pessanha. Agricultura Familiar (verbete). In: MOTTA, Márcia (Org.). Dicionário da Terra. Rio de Janeiro: Civilização Brasileira, 2005. p. 23-26.

Agricultura familiar: quantos ancoradouros! In: FERNANDES, Bernardo Mançano; MARQUES, Marta Inez Medeiros; SUZUKI, Julio Cesar (Org.). Geografia agrária: teoria e poder, v. 1. São Paulo: Expressão Popular, 2007. p. 211-270.

NOVAES, Regina Reyes. A CUT no campo: dissolver a neblina. Teoria \& debate, n. 8, nov./dez. 1989. Disponível em: http://csbh.fpabramo.org.br/o-que-fazemos/ editora/teoria-e-debate/edicoes-anteriores/trabalhadores-cut-no-campodissolver-neblin

PICOLOTTO, Everton Lazzaretti. A formação de um sindicalismo de agricultores familiares no Sul do Brasil. Sociologias, Porto Alegre, v. 16, n. 35, p. 204-236, 2014a.

Os atores da construção da categoria agricultura familiar no Brasil. Revista de Economia e Sociologia Rural, Brasília, v. 52, suppl.1, p. 63-84, 2014b. 
SCHMITT, Claudia Job. A CUT dos colonos: histórias da construção de um novo sindicalismo no campo no Rio Grande do Sul. In: NAVARRO, Zander (Org.). Política, protesto e cidadania no campo: as lutas sociais dos colonos e dos trabalhadores rurais no Rio Grande do Sul. Porto Alegre, Editora da UFRGS, 1996, p. 189-226.

SILVA, Marcelo Kunrath. Atores, espaços e repertórios: a atuação dos movimentos sociais através das fronteiras da sociedade civil e do Estado. In: SCHERERWARREN, Ilse; LÜCHMANN, Lígia Helena Hahn (Org.). Movimentos sociais e engajamento político: trajetórias e tendências analíticas. Florianópolis: Editora UFSC, 2015. p. 133-160.

VENCESLAU, Paulo de Tarso. Sindicalismo Rural: limpar o terreno. Teoria \& debate, n. 6, abr.jun. 1989. Disponível em: https://teoriaedebate.org. br/1989/04/01/sindicalismo-rural-limpar-o-terreno/

Submetido em: 04/01/2018

Aceito em: 02/08/2018 


\title{
THE ESTABLISHMENT OF FAMILY FARMING AS A POLITICAL CATEGORY:AN INTERPRETATION BASED ONTHE STRUGGLES OF RURAL LABOR UNIONS IN SOUTHERN BRAZIL
}

\begin{abstract}
Stemming from southern Brazil, this article looks at the second half of the 1980s, more specifically at the initial moment of the establishment of family farming as a political category in the country. It was a time of fight for prices of goods, agricultural policy, land reform and social security policy, which took place amid complaints about the damaging effects of the "conservative modernization" and the regime that promoted it. It is in this context that the discrimination between small, medium and large producers with regard to access to public policies - raised as a flag in 1987, as rural labor unions gathering small farmers from Rio Grande do Sul have succeeded in obtaining an exemption from interests charged in rural loans during the period of the Cruzado Monetary Plan - would become part of the agenda of the Rural Labor Unions in the debate on the Farm Act, starred in the National Congress from 1989 to 1991. After the Constituent Assembly, as politicians acknowledged the demand for different public policies, such policies were drawn, with that particular audience in mind. Family farming became a familiar expression among government officials, to the point that the establishment of Pronaf may be interpreted as an expression of the acknowledgment, by the State, of the relevance of that distinction. Thus, this study aims at revisiting the debate on the establishment of the family farming category in Brazil, seeking specifically to ascertain the role of the rural labor unionism in South Brazil for the establishment of this political and analytical category.
\end{abstract}

Keywords: Family farming. Public policies. Rural social movements. 